\title{
A MATHEMATICAL MODEL FOR ABRASIVE EROSION WEAR IN COMPOSITE FE-BASED MATRIX WITH WC-CO REINFORCEMENT
}

\author{
FRANCISCO CASESNOVES ${ }^{1} \&$ ANDREI SURZHENKOV $^{2}$ \\ ${ }^{1}$ IEEE (Electrical and Electronics Engineering Institute), Mechanical Engineering, \\ Tallinn University of Technology, Estonia \\ ${ }^{2}$ Mechanical Engineering, Tallinn University of Technology, Estonia
}

\begin{abstract}
This paper presents a new functional-computational model for metal-matrix composites (MMC), specifically for coatings with coarse spherical WC-Co reinforcement. We have developed, simulated and optimized the model based on previous classical approximations. The experimental data to validate this model are the laboratory tribotest-abrasion measurements and complementary appropriate numerical reports published internationally. Programming software was designed both with nonlinear optimization and curve-fitting subroutines. Results comprise the model construction from theory to computational validation on the laboratory statistical and numerical database. Additional simulations/optimization related to other models are also shown together with conceptual details of the next generation of functional models.

Keywords: mathematical modelling, nonlinear optimization, inverse methods, reinforced metal-matrix coatings, optimization software.
\end{abstract}

\section{INTRODUCTION}

In previous publications, a series of mathematical models for tribology, erosion, corrosion, and tribocorrosion models are presented and optimized by Casesnoves et al. [1], [4], Casesnoves and Surzhenkov [2] and Suzenkov et al. [3]. In general, and to date, general simulation methods of modelling have been improved and tested.

When the second stage is concluded/verified, it is possible to proceed to tribotesting and begin to implement completely new/specific laboratory data and new findings when performing the experimental. The theoretical final phase is to optimize the mathematical framework and to prepare for the period of validation. In this key point, the inverse and forward methods are strictly applied, i.e., from empirical data towards the model and from theoretical simulations of the model to comparisons with lab database [2], [4].

The second generation of functional models in tribology comprises a series of new mathematical modelling methods based on derivable and integrable functions [2], [3]. In other words, the surfactal variety of particular reinforced metals makes it convenient to adapt the modelling on the proper stochastic distribution of compounds along the surface that is exposed to abrasive wear, plastic deformation, cutting wear, erosion of other types, corrosion or tribocorrosion. We consider here the new generation of models that can be subject to a wide number of mathematical operations as a promising field in the investigation of tribological and biotribological algorithms.

This article uses a recently published integral-differential model for matrix of Fe-based alloy with WC-Co reinforcement, and develops a series of inverse optimization simulations based on laboratory experimental data.

\section{MATHEMATICAL METHOD(S) IN MODEL DEVELOPMENT}

This section is focused on the fundamental steps to develop a mathematical model, starting from experimental and heading towards the theory. A new functional model is presented both 
within the theory and experimental framework. The engineering-rationale of the method is established on the following materials mechanics statements:

An approximation-modelling technique for the tribological, tribocorrosion, and biotribological precision measurements should involve the continuous functions of surfactal volume distribution of each well-defined constituent, i.e., the part exposed to abrasive erosion/corrosion and tribological consequences. This implies a specific range of constants and parameters for a particular mixed-material.

The validation/optimization methods for these models are related to the mathematical distribution of every element/part. Probability distributions, stochastic methods, together with several types of weight factors distribution, and specialized optimization methods are important for precision/refinements of modelling.

The wear of a material under the abrasive impact erosion conditions generally depends on its hardness and fracture roughness, and specifically on abrasive particle kinetic energy, momentum, mass/density, shape and size. All these factors are crucial to optimize the wear under the mixed impact angle (e.g., from 20 to 90 degrees) with defined kinetic energy. Metal-matrix alloys with double-cemented structure are manufactured according to these conditions.

The matrix abrasive wear mechanism studied at Tallinn University of Technology has resulted in the following outcome: abrasive wear in this type of materials-matrix may be modelled through micro-cutting wear and surface fatigue wear due to the horizontal/vertical components of the impact velocity. Micro-cutting phenomenon happens in practice when impact angles are not 90 degrees, that is, the specific applied formulation for micro-cutting rate calculation does not result in zero rate since it depends of the impact angle cosine.

In metallurgy industry, metal-matrix alloys with the double-cemented structure are manufactured by a variety of methods, including thermal spraying, cladding, and powder metallurgy techniques. The powder metallurgy method, according to this study, results to be more advantageous, as it allows to manufacture hardfacings with coarser reinforcement and significantly strong binding zone. As a practical consequence in terms of industrial production, this specific technique has shown a higher abrasive wear impact resistance.

In this study, the model construction is detailed for Fe-based self-fluxing alloy (FeCrBSi) with spherical WC-Co hard metal reinforcement extensively studied and experimented in Materials Laboratories of Tallinn University of Technology during decades. In the development of the model based on the conceptual mathematical, and analytic geometry problem present in this kind of coatings is the non-constant hardness spatial distribution in the composite material: generally, hardness of matrix, reinforcement and matrixreinforcement interface may be distinguished. As hardness has a major influence on the wear properties, its non-homogeneous distribution would mean that the actual wear rates of the matrix, reinforcement and the matrix-reinforcement interface would be different. Therefore, the material modelling is more complicated. What is meant here is a method to construct a model that can be generalized with different equations/algorithms.

In Fig. 1, the method to calculate the average stochastic distance between the half point of the matrix and interface around the reinforcement is shown and graphically explained. This method is justified according to the rationale of Fig. 2, i.e., a sharp defined border/geometry between the principal components of the hardface of the composite implies that the discontinuity is at least sufficiently defined to separate the erosion rate that occurs in both parts. Fig. 1 shows the image of matrix, hardface and transition zone in Fe-based Technology Lab]. Direct Monte-Carlo imaging-random-calculations of average distancewidth of matrix related to spherical reinforcement parts are detailed in the method (inset, black arrows). Monte-Carlo method is applied taking computational-imaging random points 


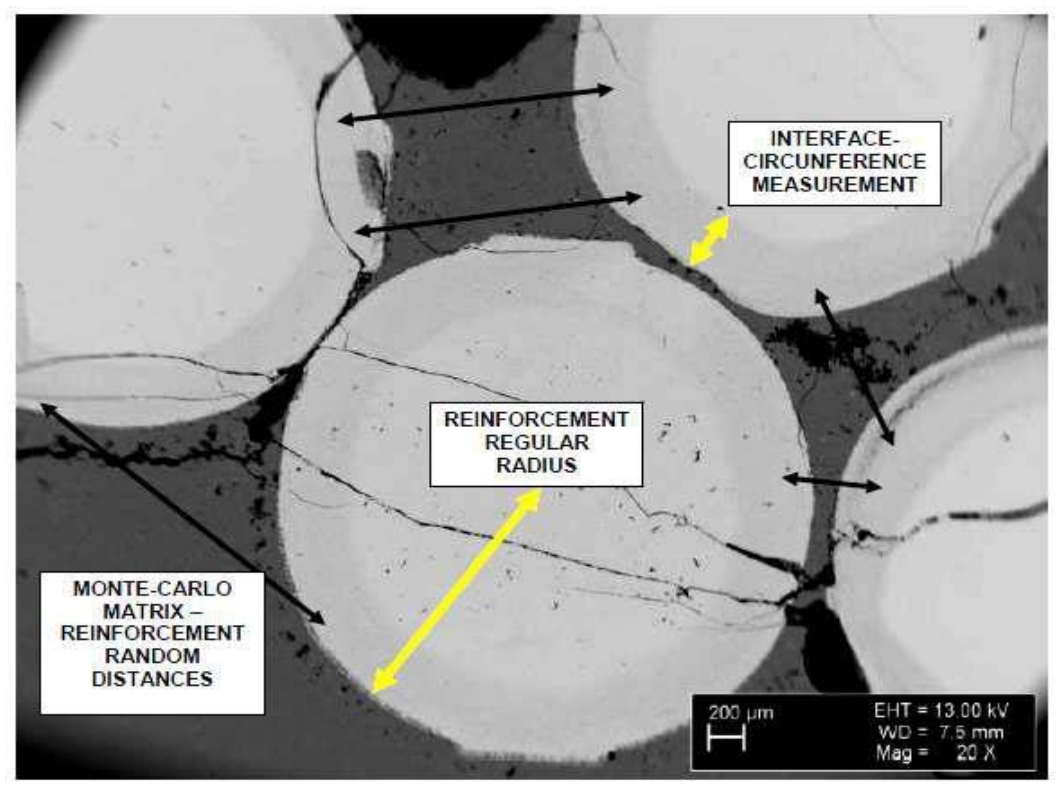

Figure 1: Image of matrix, reinforcement, and transition-binding zone in Fe-based hardfacings with coarse WC-Co reinforcement.

at interface, and afterwards calculating the average distances between each pair of points. The radius of the spherical reinforcement could be approximated as constant (inset, yellow arrow). The interface-binding zone external-circumference is also considered approximately constant (inset, yellow arrow). Distances proportion in image is provided by the Omnimet software accurately. Images of the composite were obtained with scanning electron microscope (SEM) EVO MA-15 at Tallinn University of Technology Lab [Optical microscope Axiovert 25 (Carl Zeiss) and Buehler ${ }^{\circledR}$ Omnimet $^{\circledR}$ software].

Weibull distribution is considered more applicable, in our criterion, for those hardfaces that have sufficiently mixed materials whose reinforcement grains are small enough. In those hardfaces, there are a minimum of two compounds, and the total composition can be approximated to a mixture with different proportions of its constituents, spatially distributed along the surface. For this type of structure-composition, eqns 1 and 2 are applicable, see Fig. 2. This concept is also illustrated and explained graphically in Fig. 2. Weibull distribution, Kleis and Kulu [5], has been extensively used at Tallinn University of Technology, Materials Engineering Division, in a large series of contributions and is expressed as follows:

$$
\begin{gathered}
F(H)=1-e^{-\left[\left(\frac{H}{H_{0}}\right)^{m}\right]}, \\
F(H)=1-e^{-\left[\left(\frac{H-H_{\text {minimal }}}{H_{0}}\right)^{m}\right],}
\end{gathered}
$$

where $\mathrm{H}$ is hardness, and $\mathrm{m}$ is the Weibull shape factor, while $\mathrm{H}_{0}$ is the mean hardness value. The constant $\mathrm{m}$ varies according to the type of statistical distribution, e.g., exponential, normal, log-normal, etc. However, in metals the second approximation is also used. In that formula, the minimum hardness value, $\mathrm{H}_{\text {minimum, }}$ is used. These are basically the mathematical 
concepts employed to obtain more advanced equations/models for combining the different types of erosion, such as brittle, fatigue, cutting that could occur.

The more Monte-Carlo calculations, are performed to obtain average distances, the higher the number of samples of hardface stochastic measurements, the better accuracy/refinement is reached for erosion/tribology modelling. In other words, instead of using previous statistical distributions, each different hardface well-defined in shape and geometry has a matrix and reinforcement hardness spatial distributions that can be transformed in continuous functions integrable and derivable. This is the core of the model of this research. Table 1 presents, details of experimental samples and composition, i.e., the initial lab measurements group to develop/justify the theory of the model and subsequent additional modelling simulations/optimizations.

The theoretical concepts/fundamentals to develop this Integral-Differential model are shown in Fig. 2. The most complicated models are those in hybrid-definition zone, i.e., they have features of geometrical/volume/shape nearly-clear characteristics and at the same time, composition-weight is distributed almost regularly along the hardface. Proportional methods, Luenberger [8], based on the combined equations derived from eqns 1 and 2 have also been developed. In Table 2, examples of experimental data of matrix hardness carried out at Tallinn University of Technology Mechanics Lab. These 43 values were implemented to construct the mathematical model for the matrix.

Fig. 2 shows the flow-chart-caption of the modelling ideas/concepts for the second generation of tribology mathematical modelling. When the volume/geometrical definition is sharp, the functional models are applicable. At the opposite level, is the rather proportionallymixed material framework would be better using proportional rates of compounds. At the middle, in-between of those well-defined types, are the hybrid hardfaces whose separation among components could be approximated to both previous kinds and their modelconstruction involves more mathematical difficulties [7].

It is postulated that hardness is not constant as a result of the polynomial fitting of data in Table 2; the resulting polynomial equation development is described in Section 2 of results. Therefore, for the model in the matrix, it is suggested that hardness, has a nonlinear spatial distribution according to the distance from WC-Co reinforcement spherical spots. The model used in this section shows that the functional method is a simple nonlinear Hutchings model [14] whose formulation results are modified, provided hardness is not constant. In this way, a continuous and differentiable function providing the determination of a polynomial

Table 1: Composition of experimental.

\begin{tabular}{|c|c|c|c|}
\hline \multirow{2}{*}{$\begin{array}{c}\text { Type of } \\
\text { component }\end{array}$} & \multicolumn{3}{|c|}{ Composition and proportion of experimental } \\
\hline & Type of material & $\begin{array}{c}\text { Chemical } \\
\text { composition } \\
\text { [wt.\%] }\end{array}$ & Comments \\
\hline Matrix & $\begin{array}{l}\text { Fe-based self- } \\
\text { fluxing alloy } \\
\text { (FeCrBSi) }\end{array}$ & $\begin{array}{c}13.72 \mathrm{Cr}, 2.67 \\
\mathrm{Si}, 0.32 \mathrm{Mn}, \\
2.07 \mathrm{C}, 0.02 \mathrm{~S}, \\
3.40 \mathrm{~B}, 6.04 \\
\mathrm{Ni}, \text { bal. Fe }\end{array}$ & $\begin{array}{l}\text { Matrix distribution is } \\
\text { reduced by high-size } \\
\text { of spherical } \\
\text { reinforcement }\end{array}$ \\
\hline Reinforcement & $\begin{array}{l}\text { Spherical WC- } \\
\text { Co hard metal }\end{array}$ & $85 \mathrm{WC}, 15 \mathrm{Co}$ & $\begin{array}{l}\text { Size of reinforcement } \\
\text { about } 1 \mathrm{~mm} \text { (rather } \\
\text { high) }\end{array}$ \\
\hline
\end{tabular}




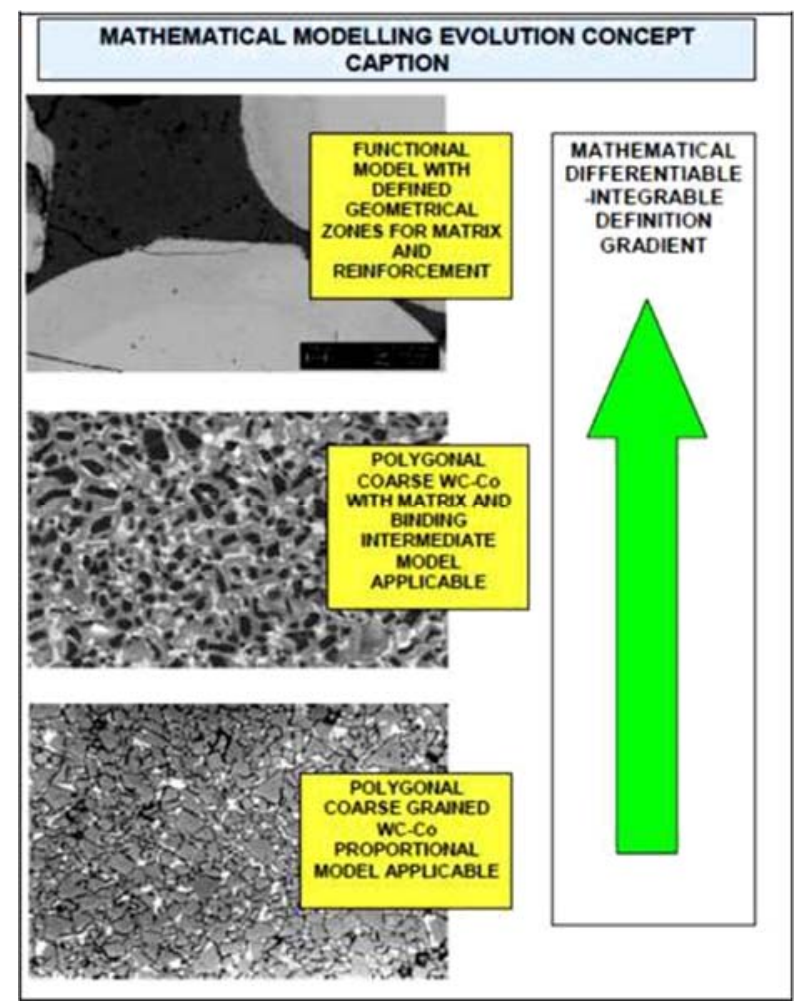

Figure 2: Graphical Imaging-Flow-Chart of concepts in the Nano-Micro-Macro tribology modelling.

Table 2: Numerical experimental data.

\begin{tabular}{|c|c|c|}
\hline \multirow[t]{2}{*}{$\begin{array}{l}\text { Number of } \\
\text { measurement }\end{array}$} & \multicolumn{2}{|c|}{$\begin{array}{c}\text { Examples of experimental data for model development } \\
\text { [TUT laboratory, Estonia] }\end{array}$} \\
\hline & $\begin{array}{l}\text { Hardness } \\
{[\mathrm{HV}]}\end{array}$ & Experimental Observations \\
\hline 4 & 861 & \multirow{4}{*}{$\begin{array}{l}\text { Steady gradient of the polynomial fitted } \\
\text { equation from half part of database sample, } \\
\text { instead the lab measurements do not show a } \\
\text { regular distribution at initial parts of the } \\
\text { measurements group. Polynomial equation } \\
\text { detailed in eqn } 5 \text { and Fig. } 3 \text {. }\end{array}$} \\
\hline 12 & 1027 & \\
\hline 30 & 1161 & \\
\hline 40 & 1219 & \\
\hline
\end{tabular}

equation $\mathrm{H}(\mathrm{s})$ can be obtained through numerical analysis. The equation reads as follows:

$$
E=\frac{K \rho[V \sin \alpha]^{2.5}}{H(s)}
$$

where $\mathrm{E}$ is erosion rate, $\rho$ is the density of the material being eroded, $\mathrm{V}$ is the initial particle velocity and $\mathrm{H}$ is the target surface hardness. $\mathrm{K}$ represents the fraction of the material removed from the indentation as wear debris and is also known as the wear coefficient. Alpha 
is the impact angle of particles. As a first approximation, let us assume that density is constant, and $\mathrm{K}$ value is well-known. Since the hardness along the surface covered by the matrix is a function determined previously, it is practical to take derivatives of wear in relation to the distance. Therefore:

$$
\begin{gathered}
\frac{d w}{d s}=\frac{d w}{d H} \times \frac{d H}{d s}=\left(K \rho[V \sin \alpha]^{2.5}\right) \times\left(\frac{-1}{H^{2}(s)}\right) \times\left(\frac{d H(s)}{d s}\right) ; \\
\text { integrating along all matrix average length, } \\
\int_{w_{0}}^{w} d w=\int_{s_{0}}^{s}\left(k \rho[V \sin \alpha]^{2.5}\right) \times\left(\frac{-1}{H^{2}(s)}\right) \times\left(\frac{d H(s)}{d s}\right) d s ;
\end{gathered}
$$

which is the total wear for the whole matrix length, and a part of the total wear of the composite metal. This type of numerical-differential modelling is applicable to composite Fe-based hardfacings with coarse WC-Co reinforcement, and extrapolated also prospectively for other types, e.g., in titanium-varieties histocompatible coatings, usually Titanium-Boride composites, for hip or knee implants. The shape-conditions are explained in the previous figures of modelling design, where the geometrical differentiation between the matrix and the reinforcement is a necessary prerequisite.

The construction of the model follows straightforward from this equation since the hardness spatial distribution at matrix is a continuous and differentiable function, instead of a series of discrete values. Given the hardness function $\mathrm{H}$ (s), at any other particular model, according to Fig. 2 hypotheses, the insertion of the function into the model of wear or other parameters subject to constraints, constitutes a new method for the determination of erosion/tribological-parameters rate.

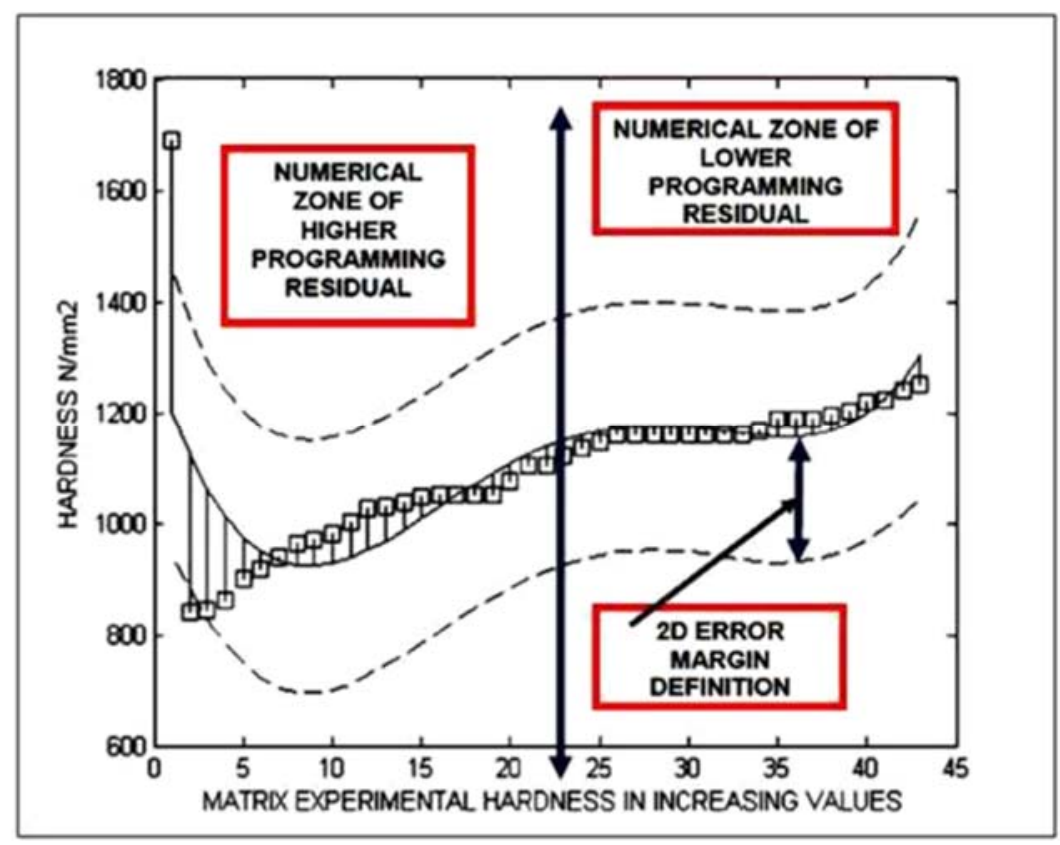

Figure 3: Computational-numerical determination of polynomial hardness distribution from the center towards the binding zone. 
Weibull distribution was not initially applied for this type of modelling since the aim was to determine the weight factors in the hardface distribution to obtain particular functions for every kind of material, according to explanations in Fig. 2. In the subsequent, the computational optimization/simulations of this model type are developed with further mathematical framework.

\section{COMPUTATIONAL RESULTS AND 2D-3D OPTIMIZATION/SIMULATIONS}

In the mathematical computational results, first, it is suggested that hardness is not constant as a result of the polynomial fitting of data in Table 2, and the equation related to the distance is as follows:

$$
\begin{gathered}
H(s)=10^{3} \times\left[(-0.0003) s^{3}+(0.0094) s^{2}+(-0.1050) s+12984\right] \\
\text { Residual of numerical fitting }=657.6564
\end{gathered}
$$

This polynomial is the mathematical definition of the variation of matrix hardness related to distances, from the lowest hardness value corresponding to the most average-distant point from any reinforcement, to the closest average-distant point to the nearest reinforcement. The residual is the mathematical sum of the differences among the fitted points of the polynomial and the experimental points obtained with lab measurements. When a residual is low, statistically and numerically the result is considered acceptable, as it is this case, see Fig. 3. As a numerical result of programming, the data from Table 2 are done in convenient subroutines for curve-optimization. In Fig. 3, the graphics of this polynomial fitting is shown with detailed explanations. A polynomial approximation was chosen for initial simplicity, and it is pointed out that hardness is in HV units and the x-axis has a direct number of measurements in increasing order. If the Monte-Carlo [7] optimal distance is implemented, the shape of the curve would be different and another equation fitting would be the optimal numerical selection. Fig. 3 shows the numerical fitting of the 4-degree-polynomial with error plotting intervals of matrix experimental hardness in intervals of average Monte-Carlo distance from the center of the matrix to the next hardface spherical spot. This optimal distance is calculated with random measurements over the images instead of the classical Weibull statistical distribution, as shown in the previous images; the hardface polynomial fitting of the reinforcement hardness is better with a 3-degree polynomial equation. It is shown that the approximation is acceptable, with the exception of the beginning of the curve, i.e., these extreme dispersed values are usually discarded for model construction. Universal hardness (HU) and modulus of elasticity (E) were simultaneously determined according to the standard EN/ISO 14577-02 using the universal hardness tester 2.5/TS (Zwick). The applied load and the indentation depth were respectively $50 \mathrm{~N}$ and $100 \mu \mathrm{m}$.

First, the Hutchings model was originally designed for plastic deformation. There are a number of formulas related to this model, from the simplest to the most complicated. This equation was selected for the sake of simplicity and clear understanding of the optimization method as follows:

$$
W=\frac{K \rho U^{2}}{2 H},
$$

where $\mathrm{W}$ is erosion rate, $\rho$ is the density of the material being eroded, $\mathrm{U}$ is the initial particle velocity and $\mathrm{H}$ is the target surface hardness. $\mathrm{K}$ represents the fraction of the material removed from the indentation as wear debris and is also known as the wear coefficient. First, the value of $\mathrm{K}$ is optimized, which can be interpreted as a measure of the efficiency of the material removal process. In other words, the first step is to determine the optimal value of $\mathrm{K}$ for a random range around an interval of experimental measurements of SO3 material based on the lab tribotests of Tallinn University of Technology. That is direct application of 
the Inverse Methods Theory in engineering. The second step is to simulate the model for a range of hardness and impact velocities in an interval around the experimental velocities of abrasive impact particles. These data are shown in Table 2. The objective function is a multiobjective least squares with $\mathrm{L}_{2}$ norm. The experimental hardness was set for optimization (43 measurements), and the $\mathrm{K}$ wear coefficient is the variable to be determined. According to eqn 4 , the model of eqn 6 would be developed as follows:

$$
\begin{gathered}
\frac{d w}{d s}=\frac{d w}{d H} \times \frac{d H}{d s}=\left(K \rho V^{2}\right) \times\left(\frac{-1}{2 H^{2}(s)}\right) \times\left(\frac{d H(s)}{d s}\right) \\
\text { integrating along all matrix average length } \\
\int_{w_{0}}^{w} d w=\int_{s_{0}}^{s}\left(K \rho V^{2}\right) \times\left(\frac{-1}{2 H^{2}(s)}\right) \times\left(\frac{d H(s)}{d s}\right) d s ; \\
\int_{w_{0}}^{w} d w=\int_{s_{0}}^{s}\left(K \rho V^{2}\right) \times\left(\frac{-p_{1}(s)}{p_{2}(s)}\right) d s ; \\
\text { with } p_{1,2}(s) \text { as integrand polynomials; }
\end{gathered}
$$

Following the rationale, assuming that velocity is not constant, as it happens in practice, for instance, in the pipes with the stream of abrasive particles whose positive/negative accelerations depend on several streams [10]-[13]. Therefore, subject to these conditions, the integral-differential model becomes as follows:

$$
\begin{gathered}
d w=\frac{\partial w}{\partial H} \partial H+\frac{\partial w}{\partial v} d v=\left(K \rho V^{2}\right) \times\left(\frac{-1}{2 H^{2}(s)}\right) \times \frac{d H}{d s} \times d s+\left(\frac{K \rho}{2 H}\right) \times(2 v) d v= \\
\text { integrating along all matrix Monte-Carlo average length, } \\
\int_{w_{0}}^{w} d w=\int_{s_{0}}^{s}\left(k \rho V^{2}\right) \times\left(\frac{-1}{2 H^{2}(s)}\right) \times\left(\frac{d H(s)}{d s}\right) d s ;+\int_{V_{0}}^{V}\left(\frac{K \rho}{H}\right) \times(v) \times d v
\end{gathered}
$$

\begin{tabular}{|c|c|c|}
\hline \multirow{2}{*}{$\begin{array}{c}\text { Number of } \\
\text { measurement } \\
\text { (total measurements of } \\
\text { matrix }=43 \text { ) }\end{array}$} & \multicolumn{2}{|c|}{$\begin{array}{c}\text { Experimental data for model simulation/optimization [Tallinn } \\
\text { University of Technology laboratory, Estonia] }\end{array}$} \\
\hline & Hardness [HV] & $\begin{array}{l}\text { Abrasive Particles Energy - AIEW } \\
\text { (abrasive impact erosion wear) }\end{array}$ \\
\hline 4 & 861 & Particle size $0.1-0.3 \mathrm{~mm}$ \\
\hline 12 & 1027 & Density $1.4 \mathrm{mg} / \mathrm{mm}^{3}$ \\
\hline 30 & 1161 & \multirow[t]{2}{*}{ Low Energy Range } \\
\hline 40 & 1219 & \\
\hline 4 & 861 & \multirow{2}{*}{ 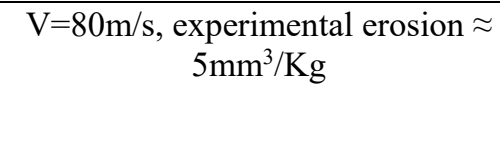 } \\
\hline $\begin{array}{l}\text { Experimental lab data } \\
\text { for optimization }\end{array}$ & $\begin{array}{c}\mathrm{V}=40 \mathrm{~m} / \mathrm{s}, \text { experimental } \\
\text { erosion } \approx 1 \\
\mathrm{~mm}^{3} / \mathrm{Kg}\end{array}$ & \\
\hline
\end{tabular}

The matrix data from the lab measurements of matrix abrasive erosion are detailed in Table 2. Table 3 shows the numerical values of hardface hardness from lab experimental measurements. Composition of alloy-reinforced experimental samples is $70 \mathrm{FeCrBSi}, 30$ WC-Co whose data was implemented for optimization of K wear coefficient in eqn 6 . Particle size and energy is explained also [Tallinn University of Technology Laboratory].

Table 3: Complementary parameters for optimization. 
The first simulation of nonlinear least squares algorithm without constraints was designed with a classical formulation as follows:

$$
\begin{gathered}
\text { minimize, } \\
F(\vec{x})=\sum_{i=1}^{i=N}\left\|H_{i}-f(\vec{x})\right\|^{2} ; \text { with } f(\vec{x})=\frac{K \rho V^{2}}{2 W},
\end{gathered}
$$

where $\mathrm{H}_{\mathrm{i}}$ values are obtained through experimental, Table 2, and wear, w, was also experimentally determined. $\rho$ is density, $v$ velocity and $\mathrm{K}$ wear constant whose optimal value is determined by the programming software. This algorithm is developed for the first velocity, graphical determination of this objective function is shown in Fig. 3 and running program results are included in Table 3 . The representation of the programming of eqn 9 is presented in Fig. 4. The objective function (OF) nonlinear optimization results for Table 1, $\mathrm{N}=43$, and equation model of eqn 6 . The impact velocity is $40 \mathrm{~m} / \mathrm{s}$. Results are acceptable with a Global Minimum (GM) sharply determined and running time is lower than a second. GM is caught up by the cursor and residual is about 500, figure which can be considered acceptable. Constraints were not set in this program.

Table 4 shows detailed numerical data obtained that was obtained from nonlinear optimization of eqns 9 and 10. Experimental values, impact velocity, material density, and all parameters implemented are from laboratory measurements results. Additionally, in Fig. 5 , the 3D surfactal simulation and graphical optimization results for Table 3 and model of eqn 6 . The impact velocity is $40 \mathrm{~m} / \mathrm{s}$. Results are acceptable with a Global Minimum and Global Maximum sharply determined that verifies the optimization software results. Matrices of imaging are 50x50.Range of simulation is around GM of algorithm of eqn 9, and hardness interval is [600 1300], which covers the experimental values of Table 3.

In Fig. 5, the results of 3D surfactal simulation and graphical optimization for Table 3 and model of eqn 6 are shown. The impact velocity is $40 \mathrm{~m} / \mathrm{s}$. Results are acceptable with a Global Minimum and Global Maximum sharply determined that verifies the optimization software results. Matrices of imaging are 50x50. Range of simulation is around Global Minimum of algorithm of eqn 9, and hardness interval is [600 1300], which covers the experimental values of Table 3.

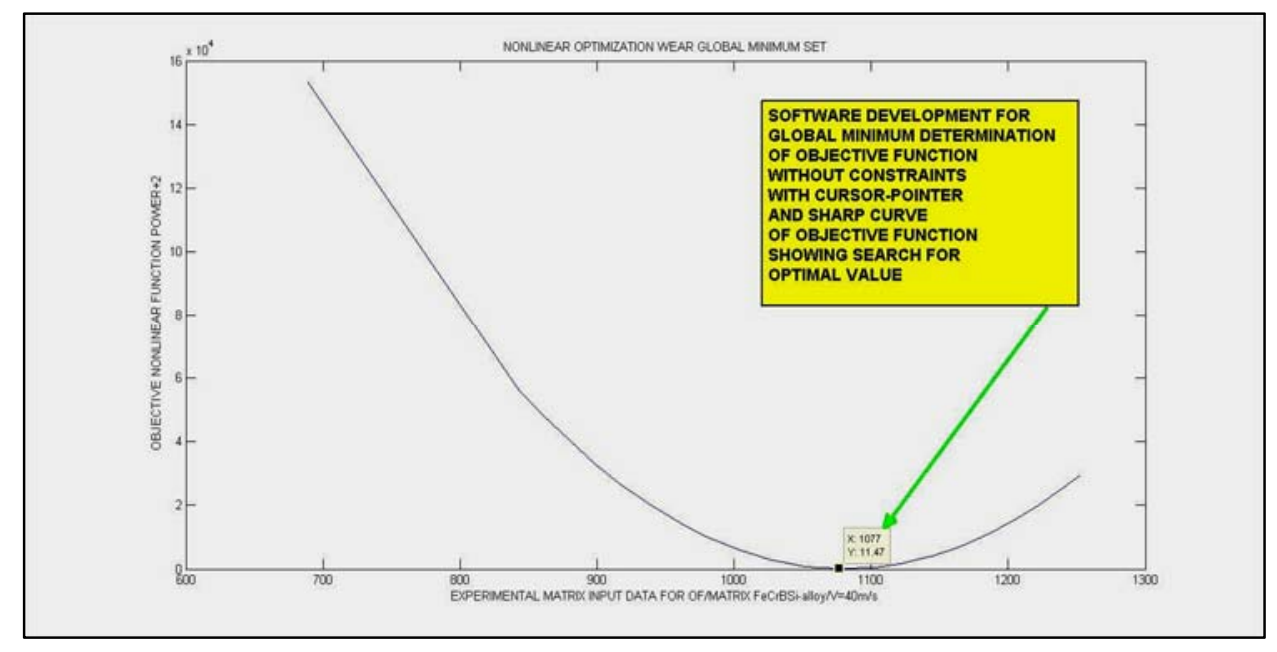

Figure 4: 2D graphical optimization result of eqn 9 with Global Minimum pointed. 
Table 4: Constrained and unconstrained numerical optimization.

\begin{tabular}{|c|c|c|c|}
\hline \multicolumn{4}{|c|}{ Simulation group 1} \\
\hline Search point & $\begin{array}{c}\text { Optimal k value (inverse } \\
\text { method) v particles = } \\
40 \mathrm{~m} / \mathrm{s}\end{array}$ & \multicolumn{2}{|c|}{ Residual of objective function (OF) } \\
\hline $\mathrm{X}=1$ & 0.9646 & \multicolumn{2}{|c|}{838.8507} \\
\hline $\mathrm{X}=5$ & 0.9646 & \multicolumn{2}{|c|}{838.8507} \\
\hline$X=20$ & 0.9646 & \multicolumn{2}{|c|}{838.8507} \\
\hline Comments & \multicolumn{3}{|c|}{$\begin{array}{l}\text { Acceptable result for optimization low residual of OF global } \\
\text { minimum exact for any search point }\end{array}$} \\
\hline \multicolumn{4}{|c|}{ Simulation group 2} \\
\hline Search point & $\begin{array}{c}\text { Optimal k value } \\
\text { (inverse method) v } \\
\text { particles }=80 \mathrm{~m} / \mathrm{s}\end{array}$ & $\begin{array}{c}\text { Constraints, } \\
\text { Intervals, } \\
\text { LB: Lower bound, } \\
\text { UB: Upper bound }\end{array}$ & $\begin{array}{c}\text { Residual of } \\
\text { objective function }\end{array}$ \\
\hline$[20,15]$ & {$[0.7424,3.0787]$} & $\begin{array}{c}\mathrm{LB}=[1 / 2,0.2] \\
\mathrm{UB}=[3 / 2,4]\end{array}$ & 838.8507 \\
\hline$[10,15]$ & {$[0.6334,2.6265]$} & $\begin{aligned} \mathrm{LB} & =[1 / 2,0.2] \\
\mathrm{UB} & =[1.5,3]\end{aligned}$ & 838.8507 \\
\hline$[1,15]$ & {$[0.7214,2.9915]$} & $\begin{array}{c}\mathrm{LB}=[1 / 2,0.2] \\
\mathrm{UB}=[1.5,3]\end{array}$ & 838.8507 \\
\hline Comments & \multicolumn{3}{|c|}{ Similar values but not equal, good residual } \\
\hline
\end{tabular}

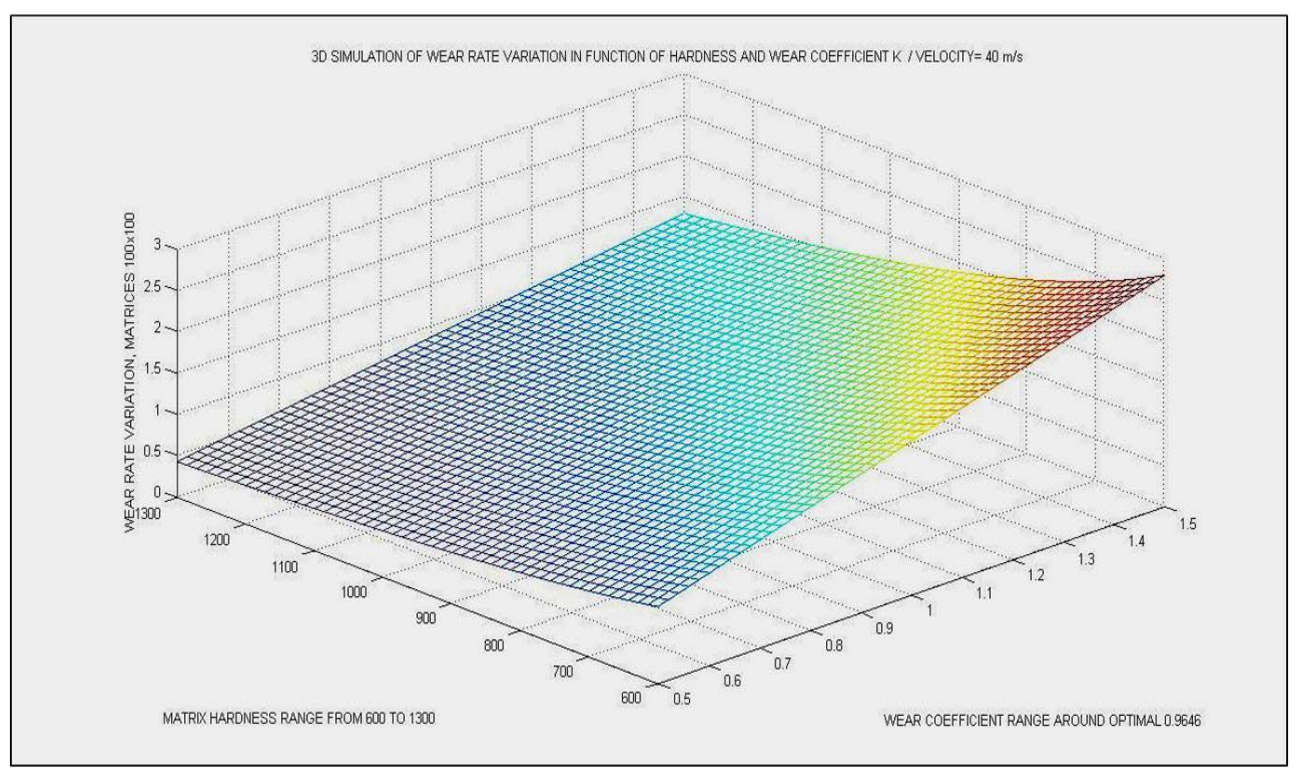

Figure 5: Graphical Optimization surfactal-programming implementation for eqn 9 (Casesnoves and Suzenkov [2]). 
The second group of simulations with constraints in Table 4 is intended for using the same hardness data but with an extended wear interval for the wear rate whose central point is the experimental value obtained in tribotesting. The determination of $\mathrm{K}$ in the constraints is also in an interval centered in the value of $\mathrm{K}$ determined without constraints. What is meant here is the multiple options available for nonlinear optimization of a model. The mathematical algorithm was designed for the model with constraints, but in terms of simple formulation. The algorithm of the Objective Function with constraints reads as follows:

$$
\begin{gathered}
\text { minimize, } \\
F(\vec{x})=\sum_{i=1}^{i=N}\left\|H_{i}-f(\vec{x})\right\|^{2} ; \text { subject to, } a_{1} \leq K \leq b_{1} ; a_{2} \leq W \leq b_{2} ; \text { with, } f(\vec{x})=\frac{K \rho V^{2}}{2 W},
\end{gathered}
$$

where $a_{i}$ and $b_{i}$ are the lower and upper boundaries of the constraints. The result of programming of this algorithm with appropriate subroutines is not too complicated, although with the number of parameters in the multi-objective nonlinear optimization increasing, the search for global or even local minima becomes more difficult.

To summarize the graphical presentation, Fig. 6 shows the nonlinear optimization results of objective function (OF) for Table 3 and constrained optimization algorithm of eqn 10. The impact velocity is $80 \mathrm{~m} / \mathrm{s}$. Results are acceptable with a Global Minimum sharply determined and running time is lower than a second. However, the search with upper and lower constraints and 2 parameters does not always determine very close values.

According to the numerical values, graphical simulations and optimization of the equations, the mathematical development of the new model has been presented properly. When the number of variables optimization in the nonlinear least squares objective function increases, the different values for the minima vary, which occurs in particular when constraints are set.

\section{CONCLUSIONS}

This article concentrates on the development of an integral-differential model of the matrix from selected alloy materials. The technical method used was based on experimental testing, with a new concept in the interpretation of the basic parameters that constitute an erosion model. The steps towards the modelling definition were justified with strict mathematical background, i.e., after the presented contribution, with Integral-Differential model and Graphical Nonlinear Optimization method. The model was built for the composite material, comprised of $\mathrm{FeCrSiB}$ alloy matrix and spherical WC-Co reinforcement (matrix/reinforcement ratio $70 \%$ vol./30\% vol., respectively), assuming that hardness spatial distribution in the matrix may be numerically calculated by a 4-degree-polynomial. The computer simulation showed a proper compatibility of the proposed model with the results of the laboratory tests. This method is a mathematical approach. The details of the contributions to macroscopic yielding over the eroding surface which are directly related to hardness are not considered.

The study was complemented with computational software results for nonlinear optimization and simulations of the equations that are presented; numerical data were clarified for sharp learning in tables and images. The conclusions are related to new improvements in the second-subsequent generation of erosion-corrosion modelling methods, which are formed by continuous functions linked to the variation of metalcomponents in the surface/hardface of the materials that are under current industrial manufacturing. Our aim was intended to present the rationale of the Integral-Differential model and discuss its prospective/future applications in metallurgy material industrial processes. 


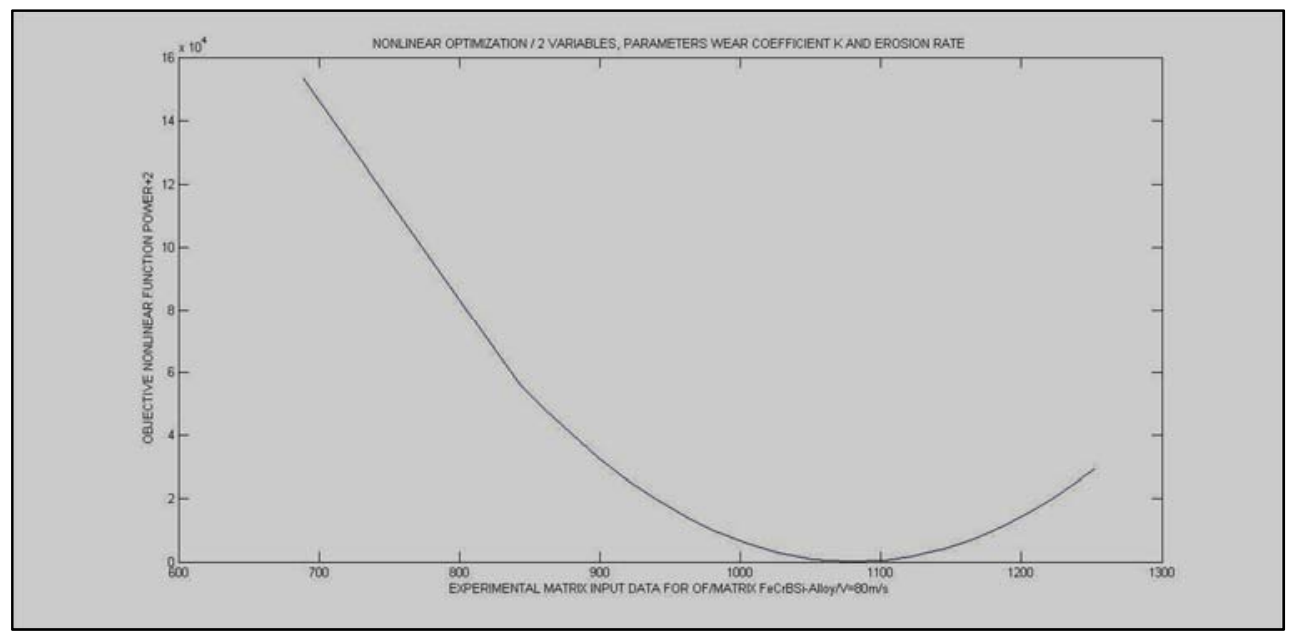

Figure 6: Constrained 2D graphical optimization results for eqn 10 , with $80 \mathrm{~m} / \mathrm{s}$ of impact speed.

\section{ACKNOWLEDGEMENTS AND SCIENTIFIC ETHICS STANDARDS}

Tallinn University of Technology is gratefully acknowledged for all the facilities for research. Tallinn University of Technology Lab, measurements done by Taavi Simson, experimental supervised by Prof. Priit Kulu and Assistant Professor Andrei Surzhenkov. This study was conducted and their contents are realized according to the European Union Technology and Science Ethics. Reference, 'European Textbook on Ethics in Research'. European Commission, Directorate-General for Research. Unit L3. Governance and Ethics. European Research Area. Science and Society. EUR 24452 EN [23]. This article contains also unique numerical data and special new improved images based on standard-tested laboratory measurements and mechanical-experimental tribotesting equipment/apparatus. Any use of data from a source is adequately recognized. Ideas from previous publications were emphasized due to a clarification aim.

\section{REFERENCES}

[1] Casesnoves F., Antonov, M. \& Kulu, P., Mathematical Models for Erosion and Corrosion in Power Plants. A Review of Applicable Modelling Optimization Techniques. 57th International Scientific Conference on Power and Electrical Engineering of Riga Technical University (RTUCON), 2016.

[2] Casesnoves, F. \& Suzenkov, A., Mathematical Models in Biotribology with 2D-3D Erosion Integral-Differential Model and Computational-Optimization/Simulation Programming. International Journal of Scientific Research in Computer Science, Engineering and Information Technology, 2(3), 2017. ISSN: 2456-3307.

[3] Surzhenkov, A., Viljus, M., Simson, T., Tarbe, R., Saarna, M. \& Casesnoves, F., Wear resistance and mechanisms of composite hardfacings at abrasive impact erosion wear. IOP Conf. Series: Journal of Physics: Conf. Series 843, 2017. 012060 doi: 10.1088/1742-6596/843/1/012060.

[4] Casesnoves, F., Antonov, M. \& Kulu, P., Mathematical Models for Erosion and Corrosion in Power Plants. A Review of Applicable Modelling Optimization 
Techniques. 2016// 57th International Scientific Conference on Power and Electrical Engineering of Riga Technical University (RTUCON), 2016.

[5] Kleis, I. \& Kulu, P., Solid Particle Erosion, Springer, 2008.

[6] Casesnoves, F., A Monte-Carlo Optimization method in Numerical Reuleaux Method for the movement analysis of pseudo-rigid bodies. 10th SIAM Conference in Geometric Design and Computing joint to Approximation Theory Conference, Texas, San Antonio, USA, 2007.

[7] Abramobitz, S., Handbook of Mathematical Functions, Applied Mathematics Series, 55, 1972.

[8] Luenberger, G.D., Linear and Nonlinear Programming, 4th Edition, Springer, 2008.

[9] Casesnoves, F., Applied Inverse Methods for Optimal Geometrical-Mechanical Deformation of Lumbar Artificial Disks/Implants with Numerical Reuleaux Method. 2D Comparative Simulations and Formulation, Computer Science Applications, 2(4), pp. $1-10$.

[10] Balamanikandasuthan, K., Arun, K. \& Palam, S.S., Design and fabrication of erosion protection shield for boiler tubes and its analysis. International Journal of Mechanical and Materials Engineering, 1(1), pp. 39-52, 2015.

[11] Hussainova, I., On micromechanical problems of erosive wear of particle reinforcement composites. Proc. Estonian Acad. Sci. Eng., 11, pp. 46-58, 2005.

[12] Kulu, P., Tarbe, R., Zikin, A., Sarjas, H. \& Surženkov, A., Abrasive wear resistance of recycled hard metal reinforced thick coating. Key Eng. Mat., 527, pp. 185-190, 2013.

[13] Simson, T. et al., Optimization of reinforcement content of powder metallurgy hardfacings in abrasive wear conditions. P. Est. Acad. Sci., 65, pp. 90-96, 2016.

[14] Surzhenkov, A., Tarbe, R., Tarraste, M., Simson, T., Viljus, M. \& Kulu, P., Optimization of hardmetal reinforcement content in Fe-based hardfacings for abrasiveimpact wear conditions. Proc. Eur. Conf. Heat Treat. 2016 and 3rd Int. Conf. Heat Treat. Surf. Eng. Automotive Applications, 11-13 May 2016, Prague, Czech Republic.

[15] Chen, Q. \& Li, D., Computer simulation of solid-particle erosion of composite materials. Wear, 255, pp. 78-84, 2003.

[16] Antonov, M. \& Renno, Effect of oxidation on erosive wear behavior of boiler steels.

[17] Hussainova, I., Kubarsepp, J. \& Shcheglov, I., Investigation of impact of solid particles against hardmetal and cermet targets. Tribology International, 32, pp. 337-344, 1999.

[18] Hussainova, I., Kubarsepp, J. \& Pirso, J., Mechanical properties and features of erosion of cermets.

[19] Crocker, L., A review of current methods for modeling erosive wear. NPL Report, 2011.

[20] Casesnoves, F., Applied Inverse Methods for Deformable Solid Dynamics/Kinematics in Numerical Reuleaux Method (NRM). International Journal of Numerical Methods and Applications, 9(2), pp. 109-131, 2013.

[21] Woytowitz, P. \& Richman, R., Modeling of damage from multiple impacts by spherical particles. Wear, pp. 120-133, 233-235, 999.

[22] Liao, H., Normand, B. \& Coddet, C., Influence of coating microstructure on the abrasive wear resistance of $\mathrm{WC} / \mathrm{Co}$ cermet coatings. Surface and Coatings Technology, 124, pp. 235-242, 2000.

[23] European Textbook on Ethics in Research, European Commission, Directorate-General for Research, Unit L3. Governance and Ethics. European Research Area. Science and Society. EUR 24452 EN. 